\title{
MOBILISASI TABUNGAN ANTARA KEUANGAN FORMAL DAN INFORMAL DALAM SISTEM KEUANGAN SYARIAH
}

\author{
Misbahul Khoir \\ Universitas Islam Lamongan \\ e-mail: misbah.coy@gmail.com
}

\begin{abstract}
Islam as a rule of life (nizdita al-hłyat) governs all sides of human life, including in terms of economic transactions, in doing saving activities too. So it also affects the institutions that receive savings funds. The definition of the Islamic financial system itself is a financial system that channels between parties who need funds and parties who have excess funds through financial products and services in accordance with the principles of sharia. The sharia principle is a principle based on the teachings of the Quran and Sunnah. In the Indonesian context, sharia principle is the principle of Islamic law in banking and finance activities based on fatwa issued by institutions that have authority in the establishment of fatwa in the field of sharia. From the background, the above description contains two important points. First, how is way of saving and investing from an Islamic point of view. Second, what is definition of Islamic Financial System. Both of these are first step in describing as problem in the scope of savings mobilization between formal and informal finance in the Islamic financial system. Islam forbids allowing idle assets, and encourages every wealth that we have to invest in the real sector. Saving is not a disbelief of the existence of sustenance from Allah. Saving is a good management process of the provision of Allah as a reflection of the attitude of our trust for sustenance given by Allah. So it can be concluded, in the teachings of Islam, the saving is effort on the alert and as part of the household financial management process. By saving we have a time-forward perspective because it not only looks at short-term expenditures, but has made predictions of preparation for the future. Saving is part of self-control. By saving, it means that we are not carried by lust to meet the fulfillment of present or short-term satisfaction, but to control the fulfillment of our desire to be able to meet the needs of the future which is much more important. Saving is not a barrier for a person to give alms or zakah. People whose faith is strong and accustomed to saving then he will be able to expel zakah well and give alms more. People who are used to saving means having good financial planning. If so, the funds that he has will be more optimal, so will be able to pay zakah well and give alms more because the funds are well managed.
\end{abstract}

Keywords: saving mobility, formal and informal finance, sharia financial system

\section{Pendahuluan}

Islam sebagai agama yang komprehensif dalam ajaran dan norma mengantar seluruh aktifitas manusia di segala bidang. Jika kita berbicara investasi dalam perspektif Islam, ada hal lain yang turut berperan dalam investasi. Investasi syariah tidak melulu membicarakan persoalan duniawi sebagaimana yang digulirkan kaum sekuler. Islam memadukannya antara dimensi dunia dan akhirat. 
Islam sebagai aturan hidup (nizd al-hłyat) yang mengatur seluruh sisi kehidupan umat manusia, menawarkan berbagai cara dan kiat untuk menjalani kehidupan sesuai dengan norma dan aturan Allah. Dalam melakukan kegiatan menabung pun demikian. Ada beberapa aspek menyangkut prinsip dan pertimbangan terkait dengan kegiatan menabung dalam Islam. Sehingga hal tersebut berpengaruh terhadap lembaga yang menerima dana tabungan, Dalam berinvestasi, Allah dan Rasul-Nya memberikan rambu-rambu, antara lain terbebas dari unsur judi (maysi $\gg$ ), terhindar dari unsur haram, dan terhindar dari unsur syubhat. Penimbunan, baik dalam bentuk uang tunai maupun dalam bentuk penimbunan barang komoditas sangat bertentangan dengan ajaran agama Islam. Penimbunan harta, seperti emas, perak, uang dan lainnya disebut iktina?. ${ }^{1}$

Kemudian pengertian sistem keuangan syariah merupakan sistem keuangan yang menjembatani antara pihak yang membutuhkan dana dengan pihak yang memiliki kebutuhan dana melalui produk dan jasa keuangan yang sesuai dengan prinsip-prinsip syariah. Prinsip syariah adalah prinsip yang didasarkan kepada ajaran al-Quran dan Sunnah. Dalam Konteks Indonesia, prinsip syariah adalah prinsip hukum Islam dalam kegiatan perbankan dan keuangan berdasarkan fatwa yang dikeluarkan oleh lembaga yang memiliki kewenangan dalam penetapan fatwa di bidang syariah. Sistem keuangan syariah didasari oleh dua prinsip utama, yaitu prinsip shar'i dan prinsip tabi'i. ${ }^{2}$ Dengan demikian, sistem keuangan syariah diformulasikan dari kombinasi dua kekuatan sekaligus. Pertama, prinsip-prinsip shar'i yang diambil dari al-Quran dan Sunnah. Kedua, prinsip-prinsip tabi'i yang merupakan hasil interpretasi akal manusia dalam menghadapi masalah masalah ekonomi, seperti manajemen, keuangan, bisnis dan prinsip prinsip ekonomi lainnya yang relevan. ${ }^{3}$

Sebagai latar belakang, penjabaran di atas mengandung dua poin penting yaitu, pertama, bagaimana menabung dan berinvestasi dari sudut pandang Islam. Kedua, pengertian sistem keuangan Islam. Kedua hal tersebut sebagai langkah awal dalam menjabarkan sekaligus sebagai batasan masalah dalam ruang lingkup mobilisasi tabungan. Sebagaimana kita ketahui bersama, bahwa alasan pertama orang menabung adalah karena adanya dana berlebih (surplus) dari pengeluaran. Selanjutnya, dana berlebih tersebut memotivasi seseorang untuk menyimpanya atau ditabung. Di sini kita mulai berangkat untuk mengkaji tentang mobilisasi tabungan menurut kaca mata sistem keuangan Islam, yang mengakomodasi sebuah kepentingan, yaitu memediasi antara dua pihak yang memiliki kepentingan berbeda antara pihak yang membutuhkan dana (defisit) dan pihak yang memiliki kelebihan dana. Sebuah sistem keuangan yang memberikan kebebasan dalam bertransaksi, bebas dari asimetri informasi dan berorientasi pada kemaslahatan bersama.

\section{Pengertian Mobilisasi Tabungan}

Pengertian tabungan menurut Undang-Undang Nomor 10 tahun 1998 tentang Perubahan atas Undang-Undang Nomor 7 tahun 1992 tentang Perbankan, adalah simpanan yang

\footnotetext{
${ }^{1}$ Farah Fuada, "Regulasi Bank Indonesia (BI) Tentang Investasi Dan Gadai Emas Serta Implikasinya Perspektif Ekonomi Islam" dalam Husen Aziz, et al (ed), Antologi Kajian Islam (Surabaya: Pascasarjana UIN Sunan Ampel press, 2001), 230.

${ }^{2}$ Saiful Azhar Rosly, Critical Issues on Islamic Banking and Financial Markets (Malaysia: Dinamas Publishing, 2005), 26-28.

${ }^{3}$ Andri Soemitro, Bank dan Lembaga Keuangan Syariah (Jakarta: Kencana, 2010) 21.
} 
penarikannya hanya dapat dilakukan menurut syarat tertentu yang disepakati, tetapi tidak dapat ditarik dengan cek, bilyet giro, dan atau alat lainnya yang dipersamakan dengan itu. ${ }^{4}$ Sedangkan menurut Keynes mendefinisikan menabung sebagai berikut:

"Excess of income over consumption expenditure in a period or as the difference in net worth at the end of period and the net worth at the beginning of the period."

Warneryd juga memberikan pengertian tentang menabung sebagai: ${ }^{5}$

"Saving meant as a rule that some consumption was postponed a safeguard future living."

Pengertian menabung sendiri menurut Surat Edaran Direksi Bank Indonesia Nomor 22/133/UPG/1989 yaitu tabungan adalah simpanan pihak ketiga pada bank yang penarikannya hanya dapat dilakukan dengan syarat:

1. Penarikan hanya dapat dilakukan dengan mendatangi bank atau alat yang disediakan untuk keperluan tersebut.

2. Penarikan tidak dapat menggunakan cek, bilyet giro serta surat perintah pembayaran lain yang sejenis.

3. Tabungan yang diselenggarakan bank dalam bentuk rupiah. ${ }^{6}$

Dalam teori konvensional, Keyness memberikan rumusan total income atau penghasilan adalah jumlah dari konsumsi dan tabungan, atau diformulasikan sebagai $\mathrm{Y}=\mathrm{C}+\mathrm{S}$. Dalam hal ini Y merupakan simbol dari penghasilan, $\mathrm{C}$ merupakan simbol dari konsumsi, sedangkan $\mathrm{S}$ merupakan simbol dari saving atau tabungan. Jika rumusan itu diubah untuk mendapatkan pengertian saving atau tabungan, maka formulasinya akan menjadi $\mathrm{S}=\mathrm{Y}-\mathrm{C}$. Jika dibahasakan dalam bentuk kalimat maka tabungan dapat didefinisikan sebagai hasil dari penghasilan yang telah dikurangi konsumsi. Contohnya, seseorang dengan penghasilan Rp. 5.000 .000 ,- per bulan dan pengeluaran yang digunakan untuk konsumsi tiap bulan yaitu Rp. 3.000.000,- maka asumsinya sisa uang yang ada yaitu Rp. 2.000.000,- akan menjadi tabungannya. ${ }^{7}$

Secara logika, tabungan seseorang akan sangat dipengaruhi oleh tingkat penghasilannya. Semakin tinggi penghasilan maka semakin tinggi pula tabungan yang dimiliki. Semakin tinggi penghasilan maka porsi uang yang akan ditabung menjadi semakin besar dan berarti kebutuhan akan menabung menjadi semakin tinggi pula.

Berbeda halnya teori konsumsi menurut ekonomi Islam. Berlakunya beberapa isntrumen dalam ekonomi Islam tentu berdampak pula kepada perilaku konsumsi bila tanpa instrumen ekonomi Islam tersebut. Beberapa Instrumen yang dapat mempengaruhi volume jumlah uang yang dialokasikan untuk konsumsi baik pada periode satu atau dua meliputi: ${ }^{8}$

\footnotetext{
${ }^{4}$ Undang-Undang Nomor 10 tahun 1998 tentang Perubahan Atas Undang-Undang Nomor 7 tahun 1992 tentang Perbankan.

${ }^{5}$ Vita Widyan Priaji, "Faktor-Faktor yang Mempengaruhi Intens Menabung di Bank Syari'ah" (Skripsi--UIN Syarif Hidayatullah Jakarta, 2011). 38.

${ }^{6}$ Surat Edaran Direksi Bank Indonesia No. 22/ 133/ UPG/ 1989.

${ }^{7}$ Vita Widyan Priaji, "Faktor-Faktor Yang Mempengaruhi”, 38.

${ }^{8}$ Adiwarman A. Karim, Ekonomi Mikro Islami Edisi Kelima (Jakarta: Raja Grafindo Persada, 2012), 117.
} 
1. Zakat; pengenaan zakat pada periode $1\left(Z_{1}\right)$ akan mengurangi $m_{l}$ yang dialokasikan untuk $\mathrm{C}_{1}$. Bila tidak ada tabungan atau peminjaman pada periode 1 maka final spending $\left(m_{1}=\mathrm{FS}=\mathrm{C}_{1}+\mathrm{Z}_{1}\right)$ sama dengan $m_{1}$.

2. Infak atau shadaqah; pengeluaran infak atau shadaqah pada I akan mengurangi $m_{1}$ yang dialokasikan untuk $\mathrm{C}_{1}$. Tidak ada tabungan atau peminjaman pada periode I maka final spending sama dengan $m_{l}$.

3. Rate of profit atau pendapatan bagi hasil, $(r p)$; apabila pada periode I ada sebagian $m_{l}$ yang dialokasikan dalam bentuk tabungan yang diinvestasikan maka final spending periode 2 (FS2) sama dengan $m_{2}$ ditambah dengan jumlah $m_{1}$ yang ditabung ditambah dengan rate of profit ( $r p)$.

Dihasilkan persamaan $\left(\mathrm{FS} 2=m_{2} \quad(1+r p) m_{l}\right)$.

Dalam konsep Islam yang dijelaskan oleh hadis Rasulullah Saw yang maknanya adalah "yang kamu miliki adalah apa yang telah kamu makan dan apa yang telah kamu infakkan".

Oleh karena itu, persamaan pendapatan menjadi:

$\mathrm{Y}=(\mathrm{C}+$ Infak $)+\mathrm{S}$

$\mathrm{Y}=\mathrm{FS}+\mathrm{S}$

Di mana : $\mathrm{FS}=\mathrm{C}+$ Infak

FS adalah final spending di jalan Allah

Jika rumusan itu diubah untuk mendapatkan pengertian saving atau tabungan, maka formulasinya akan menjadi:

$$
\mathrm{S}=\mathrm{Y}-\mathrm{FS}
$$

Jika dalam Kamus Besar Bahasa Indonesia definisi mobilisasi adalah, gerak yang mudah (cepat) atau perputaran. ${ }^{9}$ Maka dapat disimpulkan pengertian mobilisasi tabungan adalah kegiatan mengerahkan dana berlebih dari masyarakat secara efektif dan mudah untuk dihimpun sebagai keamanan apabila ada keperluan di masa mendatang.

\section{Perintah Menabung dalam Islam}

Perintah untuk mendistribusikan harta sesuai kebutuhan dan seperlunya adalah merupakan salah satu ajaran dalam Islam yang tidak menghendaki adanya pemborosan apalagi melampaui batas kewajaran. Bukan saja terkait pengelolaan uang (harta), dalam urusan makan dan minum saja diperintahkan (menjadi ibadah) tetapi ada batasan tidak boleh berlebih-lebihan. Menabung adalah tindakan yang dianjurkan oleh umat Islam, karena dengan menabung berarti seorang muslim mempersiapkan diri untuk pelaksanaan perencanaan masa yang akan datang sekaligus untuk menghadapi hal-hal yang tidak diinginkan. Di dalam alQuran, Allah telah memberikan pelajaran berharga bagi manusia tentang menabung. Anjuran menabung sudah dianjurkan semenjak zaman Nabi Yusuf, Hal tersebut dapat dilihat dalam alQuran:

\footnotetext{
${ }^{9}$ Kamus Besar Bahasa Indonesia (KBBI) dalam http://kbbi.web.id/mobilisasi diakses pada 25 Mei 2016.
} 


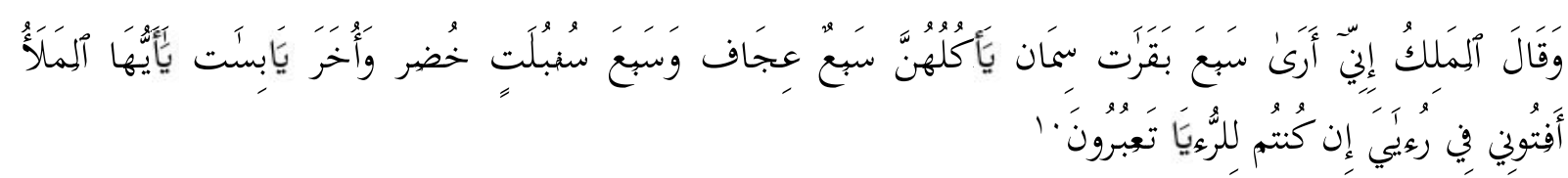

"Raja berkata (kepada orang-orang terkemuka dari kaumnya): "Sesungguhnya aku bermimpi melihat tujuh ekor sapi betina yang gemuk-gemuk dimakan oleh tujuh ekor sapi betina yang kurus-kurus dan tujuh bulir (gandum) yang hijau dan tujuh bulir lainnya yang kering. Hai orang-orang yang terkemuka, terangkanlah kepadaku tentang ta'bir mimpiku itu jika kamu dapat mena'birkan mimpi"

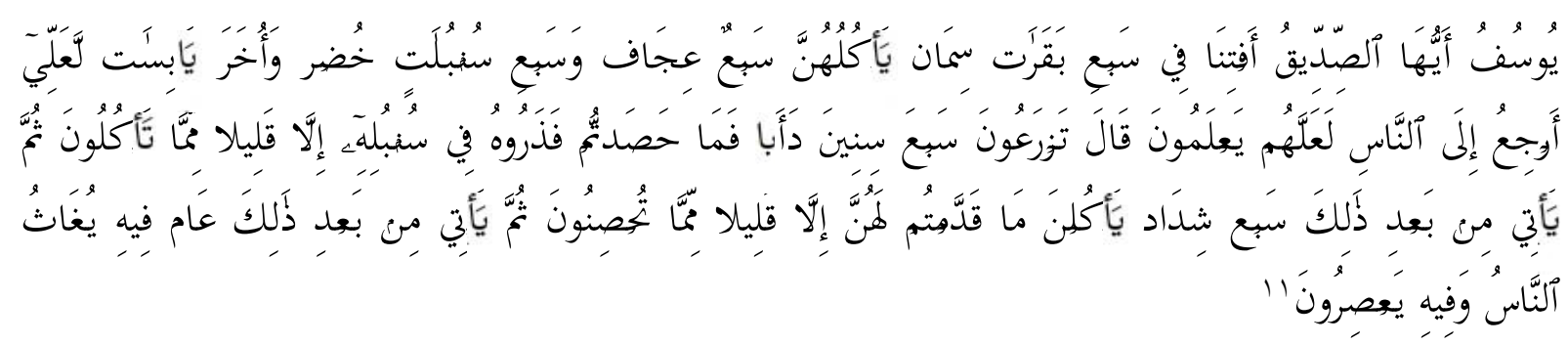

"Setelah pelayan itu berjumpa dengan Yusuf dia berseru: "Yusuf, hai orang yang amat dipercaya, terangkanlah kepada kami tentang tujuh ekor sapi betina yang gemuk-gemuk yang dimakan oleh tujuh ekor sapi betina yang kurus-kurus dan tujuh bulir (gandum) yang hijau dan (tujuh) lainnya yang kering agar aku kembali kepada orang-orang itu, agar mereka mengetahuinya". Yusuf berkata: "Supaya kamu bertanam tujuh tahun (lamanya) sebagaimana biasa, maka apa yang kamu tuai hendaklah kamu biarkan dibulirnya kecuali sedikit untuk kamu makan. sesudah itu akan datang tujuh tahun yang amat sulit, yang menghabiskan apa yang kamu simpan untuk menghadapinya (tahun sulit), kecuali sedikit dari (bibit gandum) yang kamu simpan. Kemudian setelah itu akan datang tahun yang padanya manusia diberi hujan (dengan cukup) dan di masa itu mereka memeras anggur".

Pelajaran yang di dapat dari kisah Nabi Yusuf ini sungguh luar biasa sekali. Kehidupan yang kita lalui tidak selalu indah. Adakala kita bisa bersenang-senang, hidup berkecukupan, namun kadang pula kita mengalami masa sulit, di mana kita mengalami hal hal yang di luar dugaan dan di luar kemampuan finansial kita. Biasanya pada saat hidup kita senang, lupa untuk menabung, dan pada saatnya tiba ditimpa musibah yang membutuhkan dana yang besar, baru kita menyesal kenapa kita tidak menabung di waktu mempunyai uang. Penyesalan memang selalu datang kemudian. Oleh sebab itu, Allah sudah memberikan sebuah pelajaran melalui kisah Nabi Yusuf agar umatnya tidak mengalami masa-masa sulit seperti yang dikisahkan tersebut di atas.

Tetapi bukan berarti ketika kita diperintahkan menabung, kita bersikap kikir dan tidak mempedulikan sesama. Hingga pada akhirnya kita terjebak dalam sifat kikir. Dan ketika itu pula kita menjadi orang senantiasa mengumpulkan dan menumpuk harta kekayaan. Oleh karena pandangan Islam tarhadap harta yang dimiliki manusia adalah sebagai berikut: ${ }^{12}$

1. Harta sebagai amanah (titipan) dari Allah.

\footnotetext{
${ }^{10}$ al-Quran, 12: 43.

11 al-Quran, 12: 46-49.

${ }^{12}$ Nurul Ichsan, Perbankan Shari'ah; Sebuah Pengantar (Jakarta: GP Press Group, 2014), 34.
} 
2. Harta sebagai perhiasan hidup yang memungkinkan manusia bisa menikmatinya dengan baik dan tidak berlebih-lebihan.

3. Harta sebagai ujian keimanan. Hal ini terutama menyangkut tata cara mendapatkan dan memanfaatkanya.

4. Harta sebagai bekal ibadah, yakni untuk melaksanakan perintah-Nya dan melaksanakan muamalah di antara manusia, melalaui kegiatan zakat, infak dan sedekah.

Kemudian dalam pemilikan harta dapat dilakukan sesuai dengan prinsip Islam sebagai berikut: ${ }^{13}$

1. Dilakukan melalui ( $\left.a^{\prime} m a\right)$ atau mata pencaharian (ma'i\$hah) yang halal dan sesuai aturan-Nya.

2. Dilarang mencari harta, berusaha atau bekerja yang dapat melupakan kematian, melupakan shalat dan zakat, memutuskan kekayaan hanya pada sekelompok orang saja.

3. Dilarang menempuh usaha yang haram, seperti melalui kegiatan riba, perjudian, berjual beli barang yang dilarang atau haram, mencuri, merampok, curang dalam takaran atau timbangan, melalui cara cara yang batil dan merugikan, dan melalui suap menyuap.

Dari penjelasan di atas, dapat dipastikan jika Islam membenarkan seseorang memiliki kekayaan lebih dari yang lain sepanjang kekayaan tersebut diperoleh secara benar dan yang bersangkutan telah menunaikan kewajibannya bagi kesejahteraan masyarakat, baik dalam bentuk zakat maupun amal kebajikan lain, seperti infak dan sedekah. Membelanjakan harta dalam keadaan wajar, tidak berlebihan maupun tidak kikir sesuai dalam al-Quran:

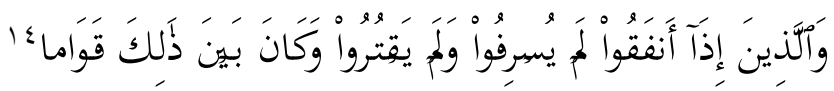

"Dan orang-orang yang apabila membelanjakan (harta), mereka tidak berlebihan dan tidak (pula) kikir, dan adalah (pembelanjaan itu) di tengah-tengah antara yang demikian."

Berdasarkan uraian di atas, maka dapat kita temukan beberapa gagasan utama, yaitu perintah menabung dan pandangan Islam terhadap harta. Apabila di awal tadi disebutkan bahwa salah satu variable konsumsi adalah pendapatan (Y), sedangkan pendapatan adalah dari hasil bekerja atau usaha seseorang, maka tidaklah berlebihan kiranya pada uraian sebelumnya dijelaskan pula tata cara Islam dalam memperoleh harta. Sampai di sini kita bisa membuat sebuah landasan cara pandang bahwa menabung memang merupakan perintah agama Islam. Kita bekerja sesuai dengan apa yang diprinsipkan dalam ajaran agama Islam, sisa pendapatan setelah di kurangi konsumsi kita tabung. Tetapi hanya sebagai motif berjaga untuk keperluan yang mendesak di masa yang mendatang. Bukan sebagai bentuk penumpukan harta kekayaan. Di atas sudah dijelaskan pula persamaan konsumsi menurut ekonomi Islam adalah Y $=$ FS + S. Di mana final spending adalah konsumsi dan infak. Berarti uang tabungan yang kita simpan sebagai tabungan adalah sisa untuk keperluan konsumsi setelah dikurangi sebagai infak.

\footnotetext{
${ }^{13}$ Ibid.

${ }^{14}$ al-Quran, 25: 67.
} 


\section{Investasikan Tabungan ${ }^{15}$}

Apalah artinya tabungan bila tidak diinvestasikan. Ia akan menjadi seonggok harta yang tidak berguna. Islam tidak menyukai adanya tindakan penimbunan harta yang sia-sia. Di satu pihak, Islam memberikan disinsentif terhadap saving yang tidak diinvestasikan, namun di pihak lain Islam memberikan insentif untuk melakukan investasi. Konsekuensi logis dari investasi adalah munculnya peluang untuk untung dan rugi.

Katakanlah seorang mempunyai harta (wealth, W) sebesar Rp. 100 juta. Harta ini dapat digunakan seluruhnya untuk investasi atau sebagiannya. Tingkat pemanfaatan harta ini sebut saja ' $v$ ' bila seluruhnya diivestasikan maka $v=1$, sedangkan bila tidak ada yang diinvestasikan maka $v=0$.

Dengan $\mathrm{v}=1$, katakanlah tingkat returnnya, $\mathrm{r}=50 \%$ atau $\mathrm{R}=\mathrm{Rp} .50$ juta. Bila diasumsikan skala usaha tidak berpengaruh pada tingkat return, yaitu tetap 50\%, bila $\mathrm{v}=0,5$ maka returnya $\mathrm{R}=\mathrm{Rp} .25$ juta. Bila dalam menginvestasikan hartanya, ia tidak melakukan sendiri, misalnya melalui kerja sama bagi hasil mudqæabah, maka return ini akan dibagihasilkan berdasarkan nisbah. Secara matematis dapat ditulis:

$$
\mathrm{Y}=(\pi \mathrm{R}) \mathrm{vW}
$$

Di mana $\quad \mathrm{Y}=$ pendapatan

$\pi=$ nisbah bagi hasil

$\mathrm{v}=$ tingkat pemanfaatan harta

$\mathrm{W}=$ harta yang ditabung

Semakin besar pemanfaatan harta (v), semakin besar pula pendapatan (Y).

Jelasnya bila $\mathrm{v}<1$, maka konsumen akan berada pada tingkat indeference curve yang lebih rendah. Dengan kata lain bila tidak seluruh saving digunakan untuk investasi, maka konsumen akan berada pada tingkat kesejahteraan lebih rendah.

Jadi dengan alasan ilmu ekonomi, kita berusaha menjelaskan bahwa salah satu maksud larangan penimbunan harta yang diatur dalam Q.S. al-Takathur adalah untuk meningkatkan kesejahteraan manusia itu sendiri.

Bagaimana dampak pendapatan keuntungan dari tabungan yang diinvestasikan terhadap prilaku konsumsi pada periode 1 dan periode 2 ?

Untuk memudahkan analisis ini, kita asumsikan barang yang dikonsumsi adalah barang normal dan tidak ada perubahan harga, maka besarnya konsumsi pada periode $1 \mathrm{C}_{1}$ adalah jumlah nominal uang pada periode $1 m_{l}$, dikurangi dengan jumlah tabungan yang diinvestasikan $S_{1}$. Kita asumsikan juga tingkat nisbah bagi hasil adalah $\pi$ dan keuntungan investasi adalah $\mathrm{R}$ maka jumlah keuntungan dari hasil investasi tersebut adalah $\pi \mathrm{R}$ dan untuk mempermudah kita tuliskan saja rate of profit dari tabungan tersebut adalah $\pi R=\mathrm{rp}(\mathrm{S})$. Maka jumlah konsumsi pada periode 2 adalah:

$$
\begin{aligned}
& \mathrm{C}_{2}=m_{2}+\left(m_{1}-c_{1}\right)+r p\left(S_{1}\right) \quad \mathrm{S}_{1}=\left(m_{1}-C_{1}\right) \\
& \mathrm{C}_{2}=\mathrm{m}_{2}+\left(\mathrm{m}_{1}-\mathrm{C}_{1}\right)+\mathrm{rp}\left(\mathrm{m}_{1}-\mathrm{c}_{1}\right) \\
& \mathrm{C}_{2}=\mathrm{m}_{2}+(1+\mathrm{rp})\left(\mathrm{m}_{1}-\mathrm{c}_{1}\right)
\end{aligned}
$$

Demikianlah, kenapa Islam melarang membiarkan asset yang menganggur, dan mendorong agar setiap kekayaan yang ada pada kita untuk diinvestasikan di sektor riil.

\footnotetext{
${ }^{15}$ Adiwarman A. Karim, Ekonomi Mikro Islami, 123.
} 
Di era modern sekarang pun orang cenderung menabung dalam bentuk uang. Sedangkan kita ketahui bersama uang dalam Islam adalah flow concept dan kapital adalah stock concept. Semakin cepat perputaran uang, akan semakin baik. Misalnya, seperti contoh pada aliran air masuk dan aliran air keluar. Sewaktu air mengalir, disebut uang sedangkan apabila air tersebut mengendap, maka disebut sebagai capital. Uang seperti air, apabila air (uang) dialirkan maka air (uang) tersebut akan bersih dan sehat (bagi ekonomi). Apabila air (uang) dibiarkan menggenang dalam suatu tempat (menimbun uang), maka air tersebut menjadi keruh atau kotor. Saving harus diinvestasika ke sektor riil. Apabila tidak, maka saving bukan saja tidak mendapat return, tetapi juga dikenakan zakat. ${ }^{16}$

Imam Ghazali juga mengecam orang yang menimbun harta dan tidak ditransaksikan atau di putar di sektor riil. ${ }^{17}$

"Jika seorang menimbun dirham dan dinar, maka ia berdosa. Dinar dan dirham tidak memiliki guna langsung pada dirinya. Dinar dan dirham diciptakan supaya beredar dari tangan ke tangan, untuk mengatur dan memfasilitasi pertukaran...[sebagai] simbol untuk mengetahui nilai dan kelas barang. Siapapun yang mengubahnya menjadi peralatan-peralatan emas dan perak tidak bersyukur kepada penciptanya dan lebih buruk daripada penimbun uang, karena orang yang seperti itu adalah seperti orang yang memaksa penguasa untuk melakukan fungsi-fungsi yang tidak cocok-seperti menenun kain, mengumpulkan pajak, dan lain-lain. Menimbun koin masih lebih baik dibandingkan mengubahnya, karena ada logam dan material lainnya seperti tembaga, perunggu, besi, tanah liat yang dapat digunakan untuk membuat peralatan. Tetapi tanah liat tidak dapat digunakan untuk mengganti fungsi yang dijalankan oleh dirham dan dinar".

\section{Mobilisasi Tabungan pada Keuangan Formal dan Informal}

Dalam rangka memobilisasi tabungan dari masyarakat baik pada keuangan formal maupun keuangan informal tidak terlepas dari kegiatan penyaluran dana atau pembiayaan. Karena kedua hal tersebut ibarat dua buah sisi mata uang yang tidak dapat dipisahkan satu sama lainnya. Yang keduanya berjalan saling beriringan dan dibungkus dalam sebuah sistem, yaitu sistem keuangan. Di mana ada mobilisasi dana tabungan di situ pasti ada kegiatan penyaluran dana. Pada uraian sebelumnya telah dibahas berbagai hal mengenai tabungan. Baik dari definisi tabungan, cara pandang Islam dalam melaksanakan kegiatan menabung, maupun bagaimana seharusnya yang dilakukan terhadap tabungan yang telah terkumpul yang sesuai dengan perspektif sistem keuangan Islam.

Istilah keuangan formal dan informal yang membedakan di antara keduanya adalah berdasarkan tempatnya di mana uang tersebut beredar. Jika uang tersebut pada lembaga keuangan formal maka disebut keuangan formal maupun sebaliknya. Baik dalam keuangan formal dan keuangan informal dalam mensukseskan gerakan mobilisasi tabungan harus berjalan seiring dengan kegiatan pembiayaan dengan melakukan prinsip-prinsip sebagai berikut:

1. Struktur organisasi. Semakin dekat dengan para nasabahnya, maka semakin banyak jumlah penabung kecilnya yang memiliki akses atas fasilitas tabungan.

\footnotetext{
${ }^{16}$ Ibid., 88.

${ }^{17}$ al-Ghazali, Ihła $>$ Uluær al-Diæ (Beirut: Daæal-Nadwah, t.th.), 92.
} 
2. Produk dan teknologi tabungan. Rekening tabungan perseorangan, sukarela, dan dengan akses yang terbuka telah terbukti paling sukses dalam menarik penabung.

3. Manajemen resiko dan likuiditas. Semua lembaga keuangan di atas mengelola resiko melalui penyaringan peminjam secara teliti, diversifikasi portofolio kredit, pemantauan peminjam, dan mematuhi kebijakan penyisihan modal yang sehat.

4. Kerangka pengaturan dan pengendalian internal. Sejumlah peraturan berdasarkan prinsip kehati-hatian dan pengawasan yang efektif menyediakan pedoman untuk praktek manajemen keuangan yang sehat dan dengan demikian melindungi kepentingan.

5. Penurunan biaya mobilisasi tabungan. Menurunkan biaya administrasi dengan merancang berbagai produk tabungan sederhana.

Berikut beberapa alasan rumah tangga membuat keputusan menabung pada lembaga formal.

1. Jaminan keamanan serta keyakinan dan kepercayaan pada tempat menyimpan tabungan, dengan kata lain, "faktor kepercayaan".

2. Likuiditas dari pilihan tabungan. Akses yang cepat atas simpanan, khususnya, sangat penting bagi rumah tangga miskin bilamana terjadi keadaan darurat dan peluang investasi muncul secara tiba-tiba.

3. Biaya transaksi, misalnya biaya pembukaan dan penutupan rekening tabungan. Waktu yang terbuang untuk pergi ke lembaga-keuangan, mengantri, dan menyelesaikan urusan surat-menyurat dapat mengakibatkan biaya tinggi yang membuat pendapatan yang tampaknya positif ternyata menjadi negatif. Dengan terpaksa penabung kecil akan lebih memilih cara tidak formal dalam menabung.

4. Tingkat suku bunga nyata. Meskipun terbukti bahwa orang di pedesaan tetap menabung bahkan dalam kondisi pendapatan negatif yang ditawarkan oleh sektor informal; di banyak negara permintaan untuk produk tabungan dari semua penabung, termasuk orang miskin, telah bertambah seiring dengan kenaikan suku bunga.

Di awal penulisan, telah penulis kemukakan bahwa kegiatan penyaluran dana dan kegiatan penerimaan dana tidak dapat dipisahkan, melainkan senantiasa berjalan bersama. Oleh karena itu, mobilisasi dana tabungan di sektor keuangan informal menjadi sangat penting keberadaannya. Bagaimana tidak, ketika UMKM (Usaha Mikro Kecil dan Menengah) tidak mempunyai akses mendapatkan pembiayaan terhadap lembaga keuangan formal karena keterbatasannya. Maka sektor keuangan informal menjadi satu satunya tempat bagi UMKM tersebut dalam memperoleh tambahan modal maupun modal awalnya. Sedangkan sektor informal tersebut memproleh dana untuk pembiayaan tentunya berasal dari tabungan masyarakat. Diungkapkan bahwa untuk mengatasi masalah pembiayaan ini, masih banyak para pedagang atau UMKM yang cenderung lebih meminjam ke paguyuban, arisan RT, kelompok yasinan, arisan PKK, ataupun kegiatan yang lain. Dengan melakukan pinjaman seperti ini, mereka bisa menambah modal untuk usahanya meskipun tidak sesuai dengan jumlah yang diharapkan. ${ }^{18}$ Sedangkan peranan UMKM terhadap perputaran roda perekonomian begitu nyata terasa di lapisan bawah. Sebagai penghasil produk dan jasa dalam

\footnotetext{
${ }^{18}$ Asis Riat Winanto dan Titi Rapini, "Peran Lembaga Keuangan Informal Terhadap Pemberdayaan Kelompok Usaha Informal”, Jurnal Ekulilibrium, Volume 12, Nomor 1 (Maret 2014), 82.
} 
skala kecil. Di sini baru terasa nyata bahwa sebuah sistem keuangan syariah berfungsi memecahkan masalah masalah ekonomi termasuk masalah yang menyangkut barang dan jasa, yaitu bagaimana cara menghasilkan.

\section{Kesimpulan}

Menabung bukanlah sikap tidak percaya akan adanya rezeki dari Allah. Menabung adalah sebuah proses pengelolaan (manajemen) yang baik atas rezeki Allah sebagai cermin dari sikap amanah kita akan rezeki yang diberikan oleh Allah. Menabung bukan untuk menimbun harta. Dalam ajaran Islam, menabung adalah salah satu upaya berjaga-jaga, di samping juga sebagai bagian dari proses pengelolaan keuangan rumah tangga. Dengan menabung, artinya kita memiliki perspektif waktu jauh ke depan. Kita tidak melihat pengeluaran dalam kacamata jangka pendek saja, melainkan sudah membuat perkiraan apaapa saja yang harus dikeluarkan pada masa mendatang, dan karenanya perlu dipersiapkan sejak sekarang.

Menabung adalah menyisihkan harta kita untuk mempersiapkan suatu pengeluaran penting pada masa mendatang, sehingga pada saatnya tiba telah tersedia dana yang memadai. Menabung adalah bagian dari pengendalian diri. Dengan menabung, kita tidak terbawa hawa nafsu untuk memenuhi pemenuhan kepuasan sekarang atau jangka pendek, melainkan mengendalikan pemenuhan keinginan kita untuk dapat memenuhi kebutuhan masa yang akan datang yang jauh lebih penting.

Menabung bukanlah penghalang bagi seseorang untuk berinfak ataupun berzakat. Berzakat dan berinfaq adalah masalah keimanan bukan karena menabung atau tidak. Banyak yang tidak suka menabung atau boros, justru dia jarang berzakat atau berinfaq karena imannya kurang.

Orang yang imannya kuat dan terbiasa menabung maka ia akan mampu berzakat dengan baik dan berinfaq lebih banyak. Orang yang terbiasa menabung, berarti memiliki perencanaan keuangan yang baik. Bila demikian maka dana yang ia miliki akan lebih optimal, sehingga akan mampu menunaikan zakatnya dengan baik dan infaq-nya pun akan lebih besar, karena dananya terkelola dengan baik.

\section{Daftar Rujukan}

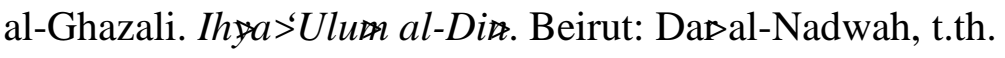

Fuada, Farah. "Regulasi Bank Indonesia (BI) Tentang Investasi Dan Gadai Emas Serta Implikasinya Perspektif Ekonomi Islam" dalam Husen Aziz, et al (ed). Antologi Kajian Islam. Surabaya: Pascasarjana UIN Sunan Ampel press, 2001.

Ichsan, Nurul. Perbankan Syari'ah; Sebuah Pengantar. Jakarta: GP Press Group, 2014.

Karim, Adiwarman A. Ekonomi Makro Islam. Jakarta: Raja Grafindo persada, 2014. . Ekonomi Mikro Islami. Jakarta: Raja Grafindo Persada, 2012.

Priaji, Vita Widyan. "Faktor-Faktor yang Mempengaruhi Intens Menabung di Bank Syari'ah", Skripsi--UIN Syarif Hidayatullah Jakarta, 2011.

Rosly, Saiful Azhar. Critical Issues on Islamic Banking and Financial Markets. Malaysia: Dinamas Publishing, 2005.

Soemitro, Andri. Bank dan Lembaga Keuangan Syariah. Jakarta: Kencana, 2010. 
Winanto, Asis Riat dan Titi Rapini. "Peran Lembaga Keuangan Informal Terhadap Pemberdayaan Kelompok Usaha Informal”, Jurnal Ekulilibrium, Volume 12, Nomor 1 (Maret 2014). 